\title{
Development of Competency Analysis System for Sewing Operators in Clothing Industry
}

\author{
Mehmet Küçük $^{\mathbf{1}^{*} \text { and Şafak Birol }}{ }^{\mathbf{2}}$ \\ ${ }^{1}$ Textile Engineering Department, Engineering Faculty, Ege University, Izmir, Turkey \\ ${ }^{2}$ TYH Izmir Research and Development Center, Turkey \\ * Corresponding Author
}

\begin{abstract}
As it is known, the ultimate goal of clothing industries is to produce and deliver products at the desired quality level by the customers. While this situation is being realized, the sustainability of the companies needs to use the resources at the optimum level. The human factor is at the top of the companies' resources, and it is aimed that the operators will actively participate in the production processes. Within the scope of the "line balancing" method, which is one of the traditional production management techniques, the number of employees, working time, and standard time of each process are taken into consideration. However, it is obvious that a new kind of process management system should be developed and different variables should be put into effect in the clothing environment whose dynamics change rapidly, has a lot of product variety, and each step is dependent on people. Within the scope of this study, it is aimed to create an "operator competence analysis" consisting of various sub-criteria for the clothing industry. In this way, it is thought that a production that is more compatible with customer requests (quality, deadline, etc.) will be achieved by improving the operators and determining the appropriate operator in a very short period of time.

It is aimed to develop an objective analysis and evaluation system in this study. The suitability of the sewing operators, who are the main actors of productivity in sewing enterprises, has been handled multidimensionally as an alternative to existing methods. In today's conditions, where production quantities depending on the model are decreasing rapidly, a 15\% reduction in model setup times has been achieved at the TYH İzmir branch, where this operator competence system developed for production lines that need to be much more agile and flexible. With this study, it is thought that a Competency Analysis System (CAS) that is much more suitable for the realities of the ready-made clothing industry, which is one of the sectors where labor-intensive production is most intense, has been gained.
\end{abstract}

Keywords: Clothing technologies, sewing line management, operation planning, line balancing, operator competency analysis. 


\section{Introduction}

The optimal allocation of work items between workstations is called "line balancing". Basically, three main methods are taken as a basis for solving this situation. In heuristic methods, process times are considered fixed, and the number of workstations is tried to be reduced. The second approach is analytical methods. These methods are also named optimization methods, mathematical programming methods. In the last approach, the simulation technique, it is essential to establish a computer model of the system to perform various experiments on this model (Eryürek et al., 2011). Line balancing is one of the common working areas of industries such as automotive and textile, which focus on production. Many methods are used in the application of line balancing in the clothing industry. In the study carried out by Eryürek, a solution to the multi-model assembly line balancing problem was sought with the "Probabilistic Line Balancing Method" and "Largest Cluster Algorithm" methods in order to achieve maximum line efficiency with the optimum machine and operator use (Eryürek, 2012). Kurşun and Kalaoğlu were used the simulation program to transfer the activities carried out in a clothing company. In this study, the steps that would form the basis for line balancing were carried out (Kurşun \& Kalaoğlu, 2010). Güner et al. sought a solution to the line balancing problem in the clothing industry with the help of five different methods (Güner et al., 2013). As it can be understood, in recent studies, the processes that constitute the production steps taken as the basis, the duration of these processes, and the production within these periods are designed to be carried out as short as possible. Therefore, the human factor has been handled in a very limited way, and even some factors that directly affect the process such as the experience of the operators working in production, the ability, and the performance have not been analyzed within the framework of concrete data.

The line balancing method constitutes the basis of this study. For the formulas and methods to be used during the study, firstly, the REFA system was used. REFA system; is the application of the methods and experiences related to the analysis and organization of the work performed in order to improve the work and to make the company work more economically by taking into account the working power and needs of the employee. The standard times of the operations are calculated by taking from the employees with the stopwatch. The basic time of the operation is found by multiplying by the current efficiency rate of the operator. The standard time is calculated by adding the relaxation allowance and unavoided delays in the REFA study system to the base time found. Relevant operators are assigned to the operations in the flow list. The process of assigning operators is a line balancing process.

In order for a clothing company to work efficiently, a balanced structure must be provided to the production factors (man, machine, and material). In order to achieve this balance, every detail of production factors must be known. Within the scope of the study, in order to determine the competencies of the operators, performance, machine knowledge, senior view, seniority level, absenteeism, overtime ability data were collected. 


\section{Material And Method}

\subsection{Material}

The material of the study is the production department of the TYH Izmir branch working on knitwear in the clothing industry. Data on 4 different sewing lines and 91 operators working in these lines were collected. The company works for 540 minutes a day, 5 days a week, except for the legal breaks. This time includes planned administrative breaks as 30 minutes lunch and 2 times 15 minutes rest. In the company, data collection is done with the help of daily production monitoring forms and recorded in the archive.

When the current situation of the company is examined, it has been determined that the traditional line balancing method is used. In this method, the system works by fixing the cycle time and minimizing the required number of stations (Table 1). For this purpose, priority relations are not violated, and tasks are grouped in sequential workstations so that the cycle time cannot be changed or exceeded. Within the scope of the current situation of the company, the following tables are used in the line balancing process.

Table 1. Line balancing example of the company

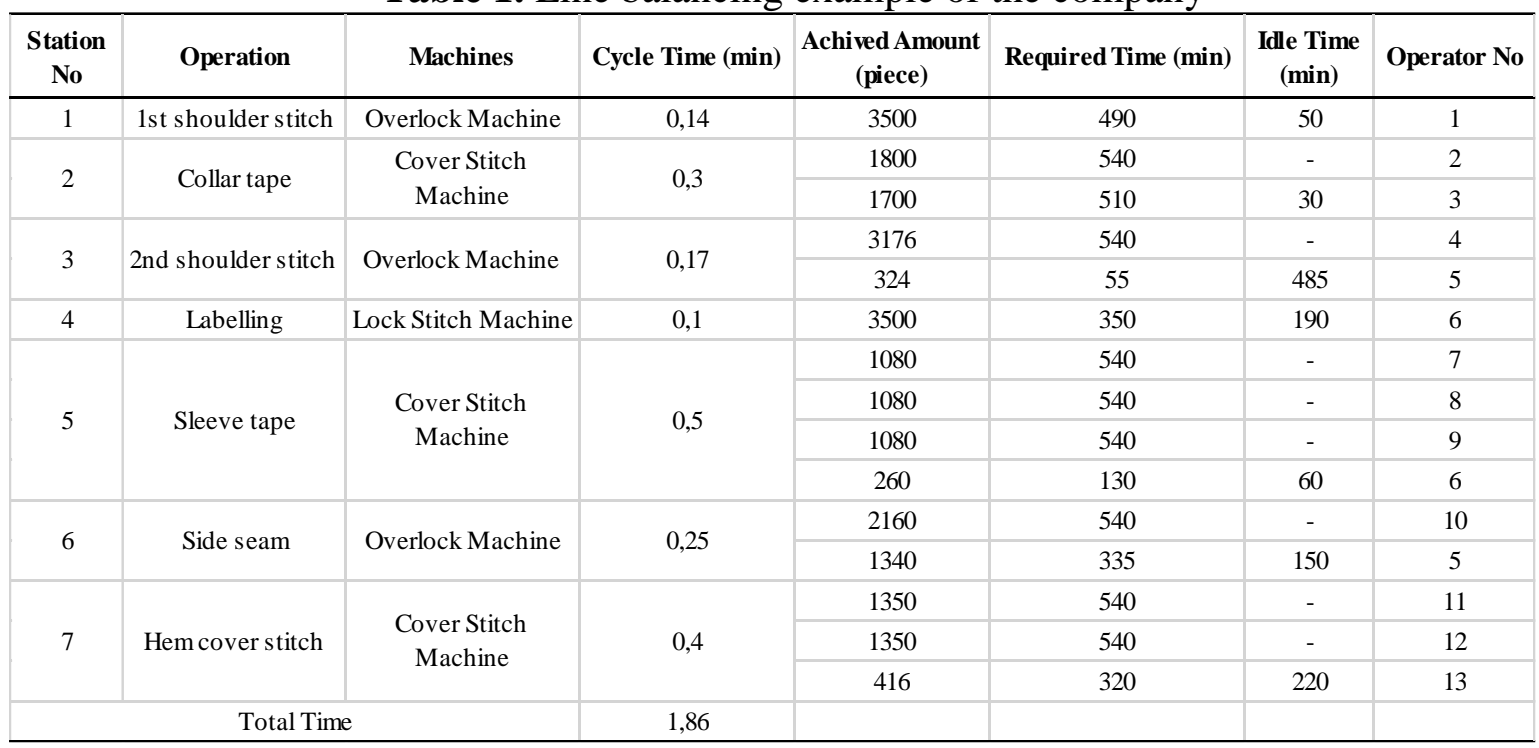

In order to develop the competency analysis system, the values of the criteria determined by archive record reviews, group interviews, observations, and document reviews were collected. In this direction, optimum working manufacturing lines were generated with the competence analysis systems created from all the data discussed.

Criteria determined by "CAS" and calculation methods developed:

Machine Knowledge: It refers to the type of machine that operators can use. Under this title, the main sewing machine groups are; lock stitch, overlock, cover stitch, and other sewing machines. The machine knowledge of the operator is calculated over the degree of mastery of the operations that can be performed on the relevant sewing machine (Table 2). 


\section{icmets}

$4^{\text {th }}$ International Conference on Modern Research in

ENGINEERING, TECHNOLOGY AND SCIENCE

AMSTERDAM, NETHERLANDS

$16-18$ July 2021

In the development of the machine criterion, the most intensively used operations in the enterprise were determined. These operations, which are used by the operators in the knitted clothing group, are classified based on 4 machine types and the difficulty levels of the operations are graded according to the 5-point system.

Table 2. Machine \& Operation Groups

\begin{tabular}{|c|c|c|}
\hline Machine Type & Operation Name & $\begin{array}{c}\text { Operation } \\
\text { Difficulty } \\
\text { Level }\end{array}$ \\
\hline Lockstitch Machine & Nape Triangle Seam & 3 \\
\hline Lockstitch Machine & Triangle Label Stitching & 3 \\
\hline Lockstitch Machine & Pocket Seam & 2 \\
\hline Lockstitch Machine & $\begin{array}{l}\text { Nape Heading Tape } \\
\text { Stitching }\end{array}$ & 4 \\
\hline Lockstitch Machine & $\begin{array}{l}\text { Washing Instruction } \\
\text { Stitching }\end{array}$ & 1 \\
\hline Lockstitch Machine & Zipper Attaching & 5 \\
\hline Lockstitch Machine & Sleeve End Stopstitch & 2 \\
\hline Lockstitch Machine & Fly Long Stitching & 2 \\
\hline Lockstitch Machine & Fly Envelope Stitching & 5 \\
\hline Lockstitch Machine & Collar & 4 \\
\hline Lockstitch Machine & Slit & 4 \\
\hline Overlock Machine & Hem Rib & 3 \\
\hline Overlock Machine & Sleeve Rib & 3 \\
\hline Overlock Machine & Sleeve Setting & 2 \\
\hline Overlock Machine & Blind Seam & 2 \\
\hline Overlock Machine & Shoulder Seam & 1 \\
\hline Overlock Machine & Collar + Hood Seam & 3 \\
\hline Overlock Machine & Side Seam & 3 \\
\hline Cover stitch Machine & Binding & 1 \\
\hline Cover stitch Machine & $\begin{array}{c}\text { Hem }+ \text { Sleeve Covering } \\
\text { Seam }\end{array}$ & 4 \\
\hline Cover stitch Machine & Tracking Sticth & 3 \\
\hline Cover stitch Machine & $\begin{array}{l}\text { Trimming Flatlock } \\
\text { Stitching }\end{array}$ & 3 \\
\hline Chain stitch Machine & Rubber Seam & 2 \\
\hline Chain stitch Machine & Shoulder Chain Stitch & 2 \\
\hline $\begin{array}{l}\text { Flat seaming (Lock) } \\
\text { Machine }\end{array}$ & Lock & 3 \\
\hline
\end{tabular}


The operators' command of the relevant machines has been calculated based on their skills and knowledge of operations. Since the degree of knowing the operation is as important as the number of different operations in the relevant machine type, the 3-point skill system was applied at this stage (Table 3).

Table 3. Machine knowledge point scale

\begin{tabular}{cc}
\hline Machine Knowledge & Point \\
\hline Low & 1 \\
Intermediate & 2 \\
High & 3 \\
\hline
\end{tabular}

The machine knowledge score of operators was evaluated separately for each kind of operation. After this evaluation was completed for all operators, the general machine knowledge score was obtained by multiplying the operator's knowledge of the operation with the difficulty value of the operation. In order to convert these points into a 100-point system, the total machine knowledge score was proportioned with the highest coefficient score that could be obtained, and the scoring system was converted to a percentage system.

Performance: It expresses the average daily net production rate in line with the operator's targets. This value is calculated over the performance of the operator to realize the daily, monthly, and annual targeted production numbers.

For instance, the operator, which is targeted to produce 1,000 units in one day, has completed 950 operations. If 900 of them are classified as good and 50 as faulty productions, the performance of this operator is calculated as $90 \%$. Therefore, the performance criterion also includes the quality parameter and is recorded as a percentage.

Senior View: Expresses the operator's senior (such as the foreman/chief) comments about the operator. The evaluations of the senior, which knows all the operators that make up the production line, were taken subjectively in the determined periods and scored out of 100 .

Seniority Level: It expresses the operator's working years (seniority) in the company. It is calculated as a percentage based on the ratio of the years of the operators in the sector and the year in which the company is in operation (21 years).

Absenteeism: It refers to the number of days that operator is absent on average per month. It is calculated as a percentage over the ratio of the total number of days that the operator is absent during the year and the total number of days that can be worked.

Overtime Ability: It refers to the flexibility of the operators to stay overtime. It is calculated as a percentage over the ratio of the number of days the operator has to work overtime during the year and the total number of days that can be spent overtime. 


\subsection{Method}

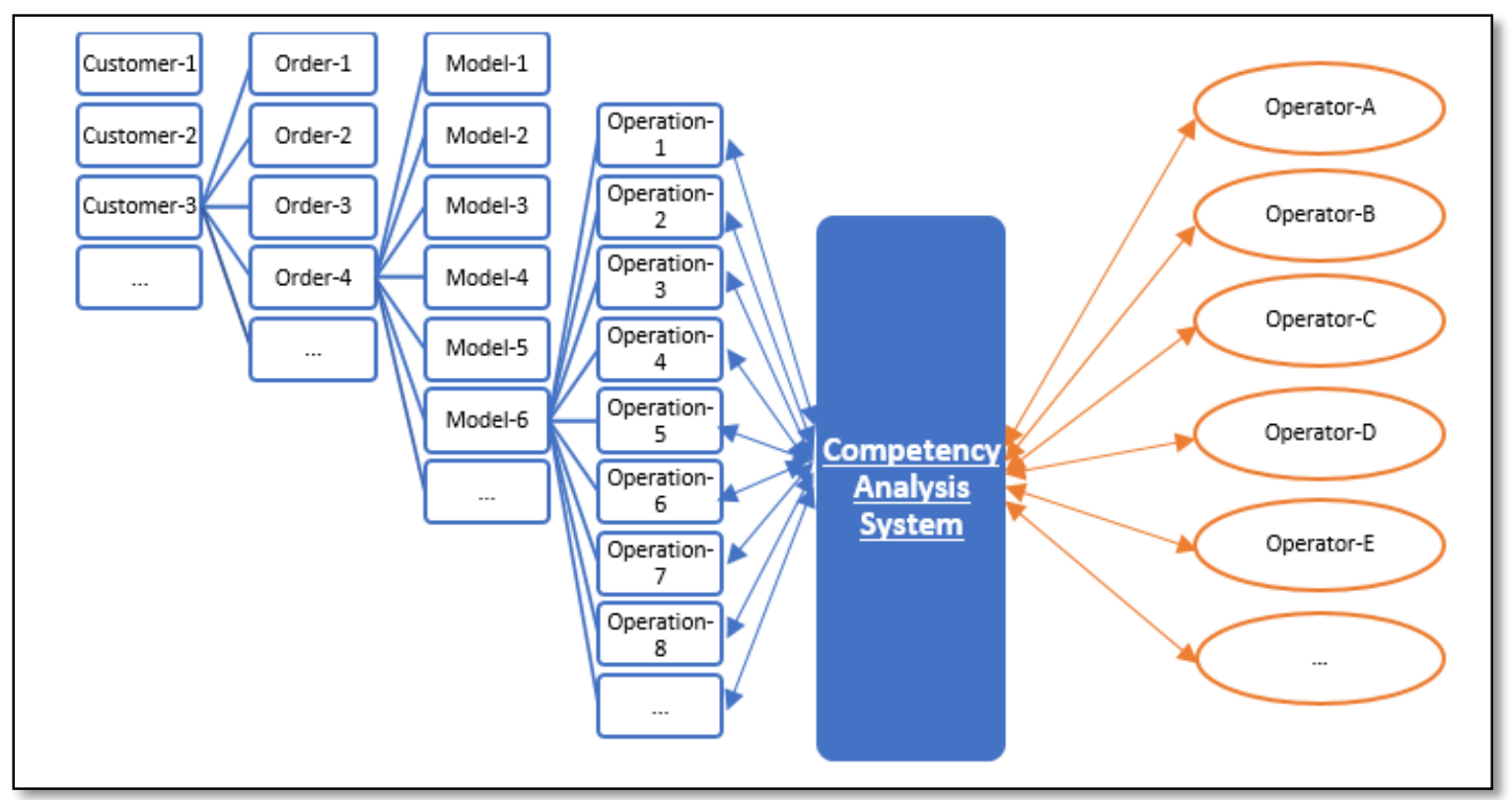

Figure 1. The line balancing scheme with the competency analysis system

The study aims to generate a new system to set up the production line in a way that will affect the production and create the least bottleneck, not only by considering the "operators' daily production value" criterion. In this direction, criteria that can evaluate the operators from various aspects were determined and the score values of each operator were calculated according to the determined criteria. The principle of the system; considering the type of machine each operator uses skillfully, whichever operator has the higher score calculated within the scope of the system, that operator is assigned to the relevant sewing line.

Since the purpose of the study is to evaluate the operator within the scope of the determined criteria and to assign it to the relevant operation, it is a requirement for the operators to carry each specified criterion on a certain scale. At this point, it is necessary to give importance to each criterion in order for the comparisons to give consistent and logical results. In this context, the pairwise comparison scale developed by L. Saaty was used to determine the importance level of each criterion relative to each other. This scale is a measurement theory based on the comparison of options on a scale of 1-9 according to a common criterion (Saaty, 1990) (Table 4).

In order to determine the criterion weights, pairwise comparisons should be made and pairwise comparison matrices should be prepared in (nxn) dimension. After the hierarchical structure of the problem is established, the criteria at the same levels are compared with each other, separately for each level. 
Table 4. Saaty scale (Saaty, 2007)

\begin{tabular}{|c|c|c|}
\hline $\begin{array}{l}\text { Intensity of } \\
\text { Importance }\end{array}$ & Definition & Explanation \\
\hline 1 & $\begin{array}{l}\text { Equal Im- } \\
\text { portance }\end{array}$ & Two activities contribute equally to the objective \\
\hline 3 & $\begin{array}{l}\text { Moderate Im- } \\
\text { portance }\end{array}$ & $\begin{array}{l}\text { Experience and judgment slightly favor one activity over } \\
\text { another }\end{array}$ \\
\hline 5 & $\begin{array}{l}\text { Strong Im- } \\
\text { portance }\end{array}$ & $\begin{array}{l}\text { Experience and judgment strongly favor one activity } \\
\text { over another }\end{array}$ \\
\hline 7 & $\begin{array}{l}\text { Very Strong } \\
\text { Importance }\end{array}$ & $\begin{array}{l}\text { Experience and judgment very strongly favor one activ- } \\
\text { ity over another }\end{array}$ \\
\hline 9 & $\begin{array}{l}\text { Extreme Im- } \\
\text { portance }\end{array}$ & $\begin{array}{l}\text { Experience and judgment extreme strongly favor one ac- } \\
\text { tivity over another }\end{array}$ \\
\hline $2,4,6,8$ & $\begin{array}{l}\text { Intermediate } \\
\text { Values }\end{array}$ & Intermediate values between the two adjacent judgments \\
\hline
\end{tabular}

Therefore, it is necessary to check whether the comparisons made by the decision-makers are consistent considering the whole hierarchy. This is determined via the "Consistency Rate (CR)". The consistency ratio is calculated for each pairwise comparison matrix, and the upper limit is required to be 0.10 for this ratio. If the rate is above 0.10 , it means that there is an inconsistency in the judgments of the decision-maker (Donegan et al., 1992).

In order to determine the weights of the criteria purposefully and effectively, a questionnaire form including pairwise comparisons of the criteria was prepared and this questionnaire was carried out as a result of face-to-face and online interviews with the people who will evaluate the questionnaire. In the determination of the weights of the criteria, a decision group including 30 people from different disciplines related to the subject (company production managers, production engineers, academicians) were subjected to pairwise comparisons through the survey. The final criteria weights were determined by taking the arithmetic average of the data based on each criterion weight and the following results were obtained. Super Decisions package program was used to evaluate the survey results (Table 5).

Table 5. The weights of the criterion

\begin{tabular}{cc}
\hline Criteria & Weight Value \\
\hline Machine Knowledge & 0,412 \\
Performance & 0,248 \\
Senior View & 0,076 \\
Seniority Level & 0,046 \\
Absenteeism & 0,134 \\
Overtime Ability & 0,084 \\
\hline
\end{tabular}


When the Consistency Rate (CR values) obtained in order to test the reliability of the evaluations were considered, it is possible to state that the data used in the methods are valid since the comparisons of the 30 respondents meet the $\mathrm{CR}<0.10$ condition.

\section{Findings}

The data obtained as a result of all field and survey studies were collected in a single table. In this table, the line number, machine knowledge, performance, absenteeism, overtime ability, senior view, and seniority level belonging to 91 operators are recorded. At the end of the table, the value of each criterion was summed in proportion to the criteria weights and the CAS score was calculated (Table 6).

Table 6. The CAS score of the operators

\begin{tabular}{|c|c|c|c|c|c|c|c|c|}
\hline $\begin{array}{l}\text { Opera- } \\
\text { tor no }\end{array}$ & $\begin{array}{c}\text { Opera- } \\
\text { tor's } \\
\text { line } \\
\text { (team) } \\
\text { num- } \\
\text { ber }\end{array}$ & $\begin{array}{l}\text { Machine } \\
\text { knowledge }\end{array}$ & $\begin{array}{l}\text { Perfor- } \\
\text { mance }\end{array}$ & $\begin{array}{c}\text { Absen- } \\
\text { teeism }\end{array}$ & $\begin{array}{l}\text { Over- } \\
\text { time } \\
\text { ability }\end{array}$ & $\begin{array}{c}\text { Sen- } \\
\text { ior } \\
\text { view }\end{array}$ & $\begin{array}{l}\text { Sen- } \\
\text { iority } \\
\text { level }\end{array}$ & $\begin{array}{l}\text { CAS } \\
\text { score }\end{array}$ \\
\hline 1 & 1 & 35 & 83 & 85 & 35 & 100 & 65 & 60 \\
\hline 2 & 1 & 61 & 86 & 76 & 31 & 65 & 45 & 66 \\
\hline 3 & 1 & 26 & 89 & 76 & 35 & 100 & 39 & 55 \\
\hline$\cdots$ & $\cdots$ & $\cdots$ & $\cdots$ & $\cdots$ & $\cdots$ & $\cdots$ & $\cdots$ & ... \\
\hline 89 & 4 & 13 & 85 & 79 & 18 & 30 & 1 & 41 \\
\hline 90 & 4 & 46 & 84 & 78 & 18 & 65 & 1 & 57 \\
\hline \multirow[t]{2}{*}{91} & 4 & 72 & 81 & 80 & 13 & 100 & 1 & 69 \\
\hline & & 0,412 & 0,248 & $\mathbf{0 , 1 3 4}$ & $\mathbf{0 , 0 8 4}$ & $\mathbf{0 , 0 7 6}$ & 0,046 & 59 \\
\hline
\end{tabular}

When the table is examined, it is seen that the average CAS score of 91 operators is 58.97. In the interviews with the production engineers and production managers in the examined enterprise, it was learned that the operators with high scores were the most qualified and satisfied operators in accordance with reality, while the operators with low scores were generally new ones. When the average competency score of the lines (teams) is examined, it is seen that the line with the highest CAS score is the 1st line (Table 7).

Table 7. The CAS score of the lines (teams)

\begin{tabular}{cc}
\hline Line No & $\begin{array}{c}\text { Average CAS } \\
\text { Score }\end{array}$ \\
\hline 1 & 62,77 \\
2 & 61,28 \\
3 & 55,86 \\
4 & 56,02 \\
\hline
\end{tabular}


All the findings obtained were shared with the company managers and suggestions were made to improve the CAS scores of the operators and the necessary training was planned. After the analysis was completed, the developed system started to be used in line balancing studies. With the multi-dimensional system being compared quickly on a single score and facilitating operator assignment decisions, an average of $15 \%$ reduction in line setup times in the enterprise has been detected.

\section{Results and Evaluations}

In today's economic conditions, market conditions mostly determine the product's price, not companies. In this case, companies should be able to offer the product that can create demand in market conditions at the demanded price. Companies may not be able to communicate directly market conditions and external factors. However, they have the opportunity of providing a competitive advantage compared to other businesses by practicing their internal factors.

Line balancing methods are the most frequently used methods to solve problems such as blockages in the workflow, delays, idle times of overloading of stations encountered in manufacturing companies. Finding new solutions like in this study has become more important in the clothing industry that is a dynamic sector where a very large number of people work. In this study,

- All operators can be evaluated objectively not only taking the performance data into account but also machine knowledge, senior view, seniority level, absenteeism, overtime ability with just one system.

- The balancing level of each line in the production department can be evaluated and each line can be compared with the others easily.

- While the operators are evaluated within the scope of the criteria discussed, the areas where they are weak can be easily identified and training can be taken to eliminate the weakness in this direction.

It is aimed to develop an objective analysis and evaluation system in this study. The suitability of the sewing operators, who are the main actors of productivity in sewing enterprises, has been handled multidimensionally as an alternative to existing methods. In today's conditions, where production quantities depending on the model are decreasing rapidly, a $15 \%$ reduction in model setup times has been achieved at the TYH İzmir branch, where this operator competence system developed for production lines that need to be much more agile and flexible. With this study, it is thought that a Competency Analysis System (CAS) that is much more suitable for the realities of the ready-made clothing industry, which is one of the sectors where labor-intensive production is most intense, has been gained.

It is thought that supporting manufacturing with this kind of new systems is a must in today's competitive environment. Thus, by evaluating operators in different ways (the criterion), production activities can be completed more efficiently. In this context, this study is intended to be a useful roadmap, especially for the clothing industry, in theoretical and practical ways. 


\section{iCmets}

$4^{\text {th }}$ International Conference on Modern Research in

ENGINEERING, TECHNOLOGY AND SCIENCE

AMSTERDAM, NETHERLANDS

$16-18$ July 2021

\section{Acknowledgement}

This article was supported by the TUBITAK 1501 program (Project No:3189129) with the collaboration of Ege University.

\section{References}

Donegan, H.A., Dodd, F.J., McMaster, T.B., (1992). A new approach to AHP decision-making, The Statistician, 41, pp. 295-302.

Eryürek, S.H., Kalaoğlu, F, Baskak, M., (2011). Assembly line balancing by using statistical method in clothing production, Tekstil ve Konfeksyion, 21 (1), 65-71.

Eryürek, S.H., (2012). Clothing assembly line design using simulation and heuristic line balancing techniques, Tekstil ve Konfeksiyon, 22 (4), 360-368.

Güner, M., Yücel, Ö., Ünal, C. (2013), Applicability of different line balancing methods in the production of apparel, Tekstil ve Konfeksiyon, 23(1), 77-84

Kurşun, S., Kalaoğlu, F., (2010). Line balancing by simulation in a sewing line, Tekstil ve Konfeksyion, 3, 257-261.

Saaty, T.L., (1990), How to make a decision: the analytic hierarchy process, European Journal of Operational Research, 48, pp. 9-26.

Saaty, T.L. and Tran, L.T., (2007), On the Invalidity of Fuzzifying Numerical Judgments in the AnalyticHierarchy Process, ISAHP 2007, Viña del Mar, Chile, August 3-6. 